\title{
Effect of COVID-19 on Students Studying in the Secondary and Higher Secondary Level
}

\section{Sudarshana Sinha ${ }^{\dagger}$}

\section{Abstract}

The novel Corona virus has been declared a pandemic due to its high transmissibility rate, influencing human life to its heights. It has affected the psychological and mental health of all people, including the functioning of various sectors. This study is based on a micro-level survey that discusses the pandemic's effect on 600 students pursuing education in secondary and higher secondary levels in Kolkata. The school students' effect was analysed based on four parametersschool, home, a shift in the medium of education from offline to online and the effect on the students' future plans, aims and ambition. The survey was conducted using a questionnaire, which was comprised of structured and semi-structured questions circulated online among the respondents. The respondents were asked to initially rank the indicators and the variables they considered the most critical cause affecting their studies. The respondents were then asked to rate the indicators on a five-point Likert scale to judge the degree of impact of the variables on the respondents.

Keywords: COVID-19; Internet Connectivity; Digital Divide; Practical Examinations; Risk; Financial Problems; Secondary and Higher Secondary Levels; Kolkata; India

\footnotetext{
${ }^{+}$PhD Scholar, Department of Humanities and Social Science, Indian Institute of Technology (IIT), Kharagpur Email: sudarshanasinha363@gmail.com

(C) 2021 Sinha. This is an Open Access article distributed under the terms of the Creative Commons Attribution License (http://creativecommons.org/licenses/by/2.0), which permits unrestricted use, distribution, and reproduction in any medium, provided the original work is properly cited.
} 


\section{Introduction}

Novel Coronavirus or COVID-19 initially originated in the Wuhan city of China (Chahrour et al., 2020; Khan et al., 2020; Khosravi, 2020; Sahu, 2020; Yanping et al., 2020). The high rate of transmission and the delay in the process of development of the vaccine is affecting people all around the world (Abdulamir \& Hafidh, 2020; Khosravi, 2020; Lai et al., 2020; Li et al., 2020). World Health Organisation has declared COVID19 to be a pandemic on 11th March 2020 which simultaneously affected different nation states at various intensities (Chahrour et al., 2020; Sahu, 2020; World Health Organisation, 2020). National Health Commission has identified COVID-19 as a type of infectious disease which affects both the physical and psychological health and wellbeing of people because of a degree of indecisiveness enshrouding it (Chahrour et al., 2020; Khan et al., 2020; Li, et al., 2020).

As various places all-round the globe have declared a lockdown to curb the rage of the Corona virus, the countries have adopted various strategies to counter it. These strategies are inclusive of various measures pertaining to travel restrictions, social distancing, selfisolation, quarantine, strengthening health care services; in addition to this several offices have adopted the option of work from home and various educational institutions have opted for the closure of offline classes and (Choudhary, 2020; Education Today News, 2020; Farooqui, 2020; Kasrekar \& Tapaswi, 2020; World Economic Forum, 2020), they have started teaching their students in an online and virtual mode. Various examinations which were to be held in schools, colleges, universities and different competitive exams have either been cancelled or postponed. Critics have stated that the closure of schools has affected more than 80 plus per cent of the students worldwide as more and more educational centres are opting for an online mode for delivering class materials and lectures (Sahu, 2020; The New Indian Express, 2020). In other words, the pandemic has dramatically changed the landscape of higher education within the past few months
(Choudhary, 2020; World Economic Forum, 2020). This pandemic has left its impact on more or less all the sectors of the economy, but education sector is one of the worst affected one out of all of them. Looking at the uncertainty, several critics had stated that arriving at a suitable long- and short- term plan, partnership management, mobility of students, technology management and ensuring effective communication process with all the stakeholders are some of the major concerns of the higher education sector (Academic Impact, 2020; Choudhary, 2020; Education Today News, 2020; The New Indian Express, 2020; The North East Today, 2020). This pandemic has also affected more than 48 per cent of the students in India who wanted to pursue studies abroad (Choudhary, 2020; Kasrekar \& Tapaswi, 2020; Zee News, 2020).

The entire paper is divided into four sections. The first section elaborates on the previously conducted research on this topic. The second section gives a brief description of the data collection, method and methodology adopted to prepare the study justifying the selection of the various indicators used in the research. The third section discusses about the indicators, their rank and the intensity with which it has affected the respondents and the impact of the research. This section is followed by concluding remarks.

\section{Literature Review}

The pandemic has affected the students, teachers and all other school authorities due to this rapid transition from offline to online mode. Scholars argue that though the online medium of education is pretty common in the universities, it is still a new thing for the school (Education Today News, 2020; Sahu, 2020). Scholars argue that though the online medium of education is pretty common in universities, it is still a new thing for the school. In this context, the studies argue that this shift in the medium requires a certain amount of infrastructural development and technical pieces of equipment such as laptops, computers, internet facilities, microphones which in most cases is lacking among the students as well as the teachers and 
hence it has caused hindrances in the immediate shift.

Extension in the duration of a semester has also resulted in financial problems for some students. This situation becomes even more difficult for international students and those associated with educational exchange programmes (Sahu, 2020; Zee News, 2020). Due to travel restrictions, some students could not return to their home town, and special arrangements had to be made for their accommodation, safety and food facilities. Instead, many institutions opted for evaluation through continuous online assignments. However, the evaluation procedure continues to be a challenge for the teachers as it is difficult to say who has adopted unfair means during an online examination. The pandemic has also affected people's mental well-being (Chunfeng, 2020; Duan \& Gang, 2020). It has created a cloud of uncertainty, anxiety, stress, feeling of hopelessness and helplessness and has also adversely affected the psychological health as people are continuously worried about their and their family's well being and economic stability (Chen et al., 2020; Khan et al., 2020; Langella, 2020; Li et al., 2020; Sahu, 2020; Yang et al., 2020). This increase in concern created by the pandemic situation has been further aggravated by the "infodemic" which has posed serious health-related concerns among people (Khan et al., 2020). According to the Behavioural Immune System Theory, in such circumstances, people tends to harbour negative emotions and thinks pessimistically; as they feel increasingly insecure about themselves (Ackerman et al., 2009; Li et al., 2020; Mortensen et al., 2010; Schaller \& Murray, 2008; Terrizzi et al., 2013). In such a circumstance there is a tendency among people to harbour avoidant behaviour as they tend to obey social norms very stringently (Houston \& Ray, 1994; Schaller et al., 2015).

Theories such as Stress theory (Aneshensel, 1992; Norris et al., 2002) and Perceived Risk theory (Weber \& Anderson, 1992; Slovic, 1987), claims that emergencies related to public health results in a greater degree of negative emotions which in turn affects their cognitive ability. It can be argued that though these negative emotions mange to keep people away from the contagious pathogens, but in the long term, this lifestyle tends to reduce immunity levels and destroys the normal functioning of the psychological mechanisms (Li et al., 2020). Scholars assert that due to uncertainty arising out of the upcoming situations; it has resulted in conflict, innumerable problems in health, relationships and mental discomfort (Li et al., 2020). People have also adopted various preventive measures but the intensity and frequency of these preventive actions as taken by people such as usage of masks, face shields, sanitizer, social distancing is dependent upon how people perceive risk and its relation to the virus (Cowling et al., 2010; Khosravi, 2020; Weerd et al., 2011; Yoko et al., 2010). Protection Motivation Theory also reinforces these arguments (Rogers, 1975).

Studies and reports (Business Insider India, 2020; Choudhary, 2020; North East Now, 2020; The Economic Times, 2020; Zee New, 2020) argue that the decision of nearly 48 per cent of the students who wanted to pursue their higher education abroad was affected by this pandemic as the chances of them securing a job over there has decreased. Thus, it has become a low return and an extremely high investment situation to be in for them. The problem is also grim for those enrolled in courses abroad as they have no clarity about their jobs or education (Gabriels \& Benke, 2020; North East Now, 2020; The Education Times, 2020; Zee News, 2020). There is however a possibility that institutes imparting higher education might shift to e-learning in the near future. Hence, it can be said that the repercussions of this pandemic will most certainly not be restricted to just the higher education sector but will spread over to all sectors and leave behind long-lasting changes in the education system (DePietro, 2020; The New Indian Express, 2020). This pandemic has also negatively affected the mobility of the students who had previously intended to travel either nationally or internationally for their academics (Education Today News, 2020; Gabriels \& Benke, 2020; Zee News, 2020). The decrease in people's income and employment opportunities has also 
affected students' ability to pay for their course fees (Academic Impact, 2020; Choudhary, 2020).

In India, e-learning is also taking place via circulating previously recorded class, conducting live online classes, distribution of study materials and assignments through various applications (The North East Today, 2020), but for the smooth functioning of this alternative system, stable infrastructural facilities, high-speed internet connections, presence of computer or smartphones have become a pre-requisite to both teachers as well as students (Farooqui, 2020; Kasrekar \& Tapaswi, 2020). However, approximately 60 per cent of the world population has access to digital platforms, and the situation is pretty grim in the developing countries who are economically less affluent and not that well versed in technology; for them, this shift in the medium from offline to online might continue to widen this gap between the haves and the have-nots (The North East Today, 2020; World Economic Forum, 2020). This shift in the medium from traditional to newer e- learning platforms continues to be a challenge for the Indian households. As per the records of the National Sample Survey in 2017-2018, only a meagre 23.8 per cent of the Indian households have access to internet facilities; this discrepancy is even higher among those staying in the rural and urban areas where only 14.9 per cent of the former and 42 per cent of the later have access to the internet (Sahani, 2020). This rapid shift to e-classrooms is also intensifying the digital divide among the students, as many of them do not have access to the proper infrastructural facilities needed for this transition. Good internet connectivity and the necessary infrastructure required for this purpose is not available to most of the two to three-tier cities and in the rural parts of the country (Education Today News, 2020; Kasrekar \& Tapaswi, 2020; The New Indian Express, 2020; The North East Today, 2020). Various platforms initiated by the Government of India have supported many initiatives to shift towards the online class. Initiatives like e-Patshala, SWAYAM,
NEAT is aimed at making content easily accessible to the students are being encouraged.

Education Today News (2020) has predicted that this shift from offline to online mediums would result in a blended education model in the near future. However, the absence of a proper atmosphere and lack of sincerity among students might also distract them from their studies (Kasrekar \& Tapaswi, 2020). Other than this, keeping a check on the students to prevent them from adopting unfair means during the online exams has also become challenging (Langella, 2020).

Previously various scholars such as (Basset \& Amhold, 2020; ICEF Monitor, 2020; Langella, 2020; Sahu, 2020; TUAC, 2020; World Economic Forum, 2020) have given a much more generalised opinion about the impact of COVID19 on the education sector (Wenjun et al., 2020). The impact of COVID-19 on the student exchange programme has been highlighted by Gabriels \& Benke (2020) and Li et al. (2020). However, there is not much literature based on this topic in the context of Kolkata; hence, this study aims to examine the impact of this pandemic on the students studying in secondary and higher secondary levels.

\section{Data Collection, Method And Methodology}

This study examines the pandemic's effect on 600 students pursuing education in secondary and higher secondary levels in Kolkata based on a micro-level survey. To accomplish the objectives, stratified random sampling was applied (Kothari, 2004). The stratification was done based on those students studying in classes $9,10,11$ and 12 . The respondents were surveyed online with the help of Google forms. The questionnaire comprised of structured and semistructured questions. The respondents were initially asked to rank their opinion following the four indicators in the order of their importance (please refer to Figure 1). Following this, the respondents were asked to rate all the indicators on a Likert scale (Jamieson, 2017) to determine the degree of impact each indicator has on the respondents' minds. 


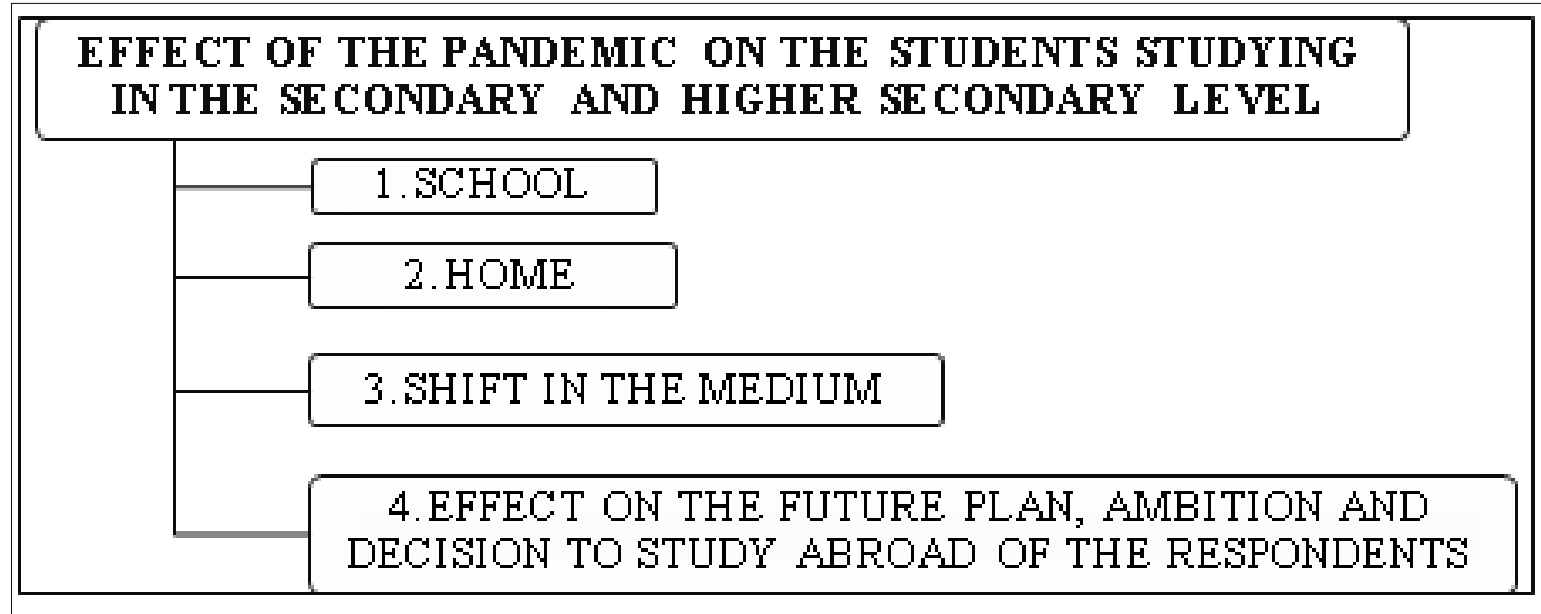

Figure1: Names of the Various Indicators which were used for the Study

\section{Justification for the Selection of the Indicators}

This shift of medium has affected the academics of various students as obtaining the required infrastructure such as laptops and undisrupted internet connection which is a prerequisite of this shift continues to be a challenge (Education Today News, 2020; Sahu, 2020). This rapid shift intensifies the digital divide among the students, those who are technologically well versed and those who are not; this situation is grimmer in developing countries as most of them do not have access to the required technology which is necessary for this purpose (Farooqui, 2020; Kasrekar \& Tapaswi, 2020; The North East Today, 2020; World Economic Forum, 2020). The situation is also critical for international students due to safety and other restrictions imposed due to the pandemic (Education Today News, 2020; Sahu, 2020; Zee News, 2020). The students are also hesitant about travelling due to the rapid spread of the disease. Reports have also suggested that this pandemic has also affected the students' inter and intra state mobility. Since people are also concerned about their employment, future and investment, it has also impacted their savings and investment options (Chen et al., 2020; Khan et al., 2020; Langella, 2020; Li et al., 2020; Yang et al., 2020). A similar situation can also be observed in case of India as the decrease in people's income and employment opportunities might have also affected the higher education system in India as it has also indirectly affected the ability of students to pay for their course fees (Academic
Impact, 2020; Choudhary, 2020). Students who are pursuing non-science stream are also reluctant to pursue their higher education abroad as the chances of them securing a job has reduced to a certain extent after the outbreak of the pandemic (Business Insider India, 2020; Choudhary, 2020; North East Now, 2020; The Economic Times, 2020; Zee News, 2020). Hence initially, these four parameters (refer to figure 1) were chosen for the study; later on, these indicators were divided into different sub-parts, which the respondents initially ranked, then the respondents were asked to rate each of them on a five-point scale.

\section{Results and Discussions}

The key purpose of the study is to examine COVID-19's effect on 600 students pursuing secondary and higher secondary levels in Kolkata. For this, 600 samples were surveyed. Among them, 125 respondents were 14 years old, 133 respondents were 15 years old, 165 respondents were 16 years old, and 177 respondents were 17 years old. The surveyed population studying in different schools in Kolkata and enrolled in classes 9, 10, 11 and 12 were selected. Out of 600 respondents, 275 respondents were male, and 375 respondents were female; among which 99 respondents were studying in class 9, 153 respondents were studying in class 10, 185 students were studying in class 11 , and 163 respondents were studying in class 12 . 
The respondents were asked if the pandemic (refer to figure 2) has affected their studies, to which 57.17 per cent mildly agreed, 26.17 per cent strongly agreed, 10.83 per cent mildly disagreed, 4 per cent strongly disagreed, and only 1.83 per cent remained neutral. The respondents were asked whether they were positively, negatively or were unaffected by the pandemic. 30.75 per cent responded that they were positively affected as they got more time to think about the subjects they wanted to pursue for their higher studies. Other than this, some of the respondents also said that they got the necessary time which was required to revise their course, practise more mock test, attend more video lectures from online sites and study those portions about which they were previously not that confident. Only 5.67 per cent stated that their academics were unaffected as they continue to pursue their studies in the same way they used to. 73.83 per cent have mentioned that their academics were negatively affected by the pandemic.

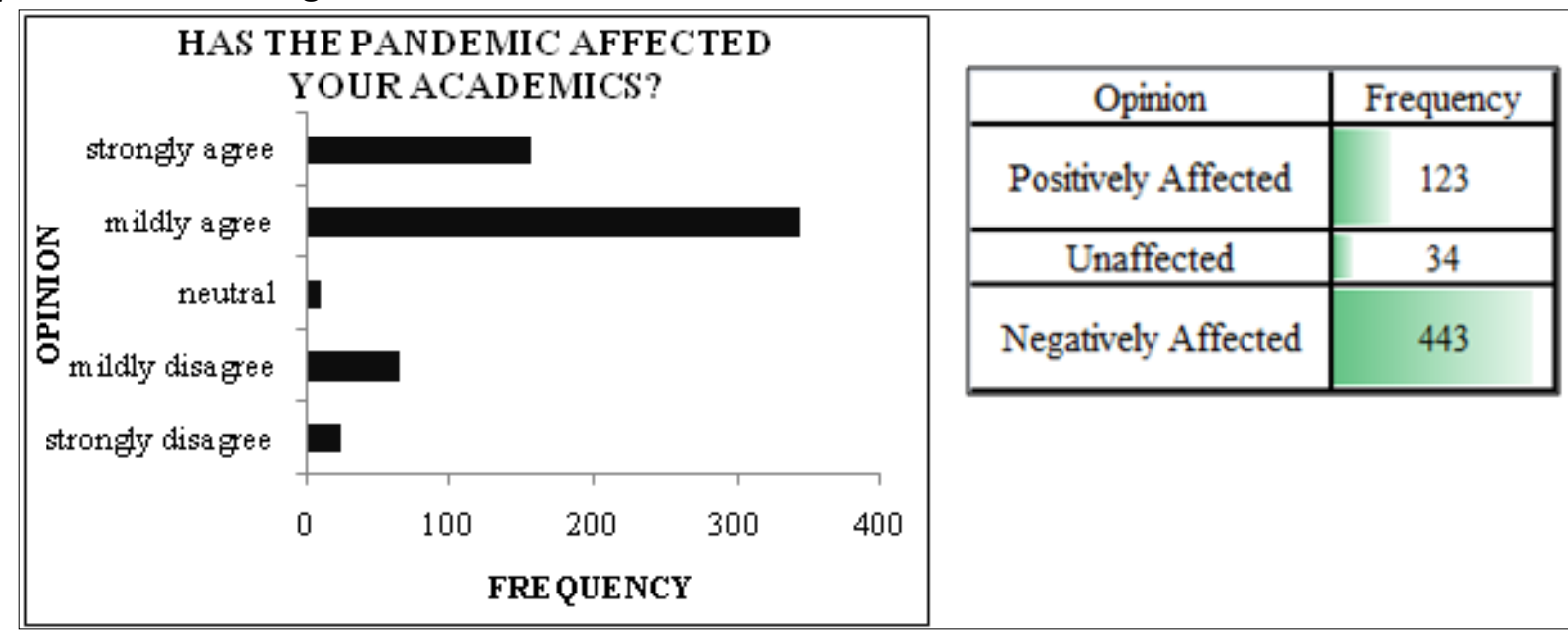

Figure 2: The Nature And The Intensity Of The Impact The Pandemic Has On The Respondents Source: Based on Primary Survey and Computed by the Author

\section{How has the Pandemic Affected the Studies}

When the respondents were asked how their studies were affected, they were initially asked to rank among the four indicators (refer to figure 3). 50.17 per cent said that they were most affected because of the shift in the medium of education from offline to online classes. 18.83 per cent were affected because of various reasons related to their school. 17.83 per cent were affected because of various factors related to their home. 13.17 per cent were affected as the pandemic situation had affected their future plans and ambition. After this initial assessment, the four indicators were further sub-divided into various sub-indicators, which are discussed below:

\begin{tabular}{|c|c|}
\hline OPTIONS & FREQUENCY \\
\hline Because of school & 113 \\
\hline Because of home & 107 \\
\hline $\begin{array}{c}\text { Problems with shift in the } \\
\text { medium of education }\end{array}$ & 301 \\
\hline $\begin{array}{c}\text { It has affected my future } \\
\text { plans and aspirations }\end{array}$ & 79 \\
\hline
\end{tabular}

Figure 3: Showing the Reasons which had Affected the Studies of the Respondents Source: Based on Primary Survey and Computed by the Author 


\section{School}

The respondents were asked to rank the most important reason as to how not going to schools has affected their studies (refer to figure 4). In response to this question 29.67 per cent participants responded of not having proper internet facilities, while 25.17 per cent mentioned that since they could not go to school, they were facing difficulties in understanding various subjects for which laboratory classes are needed. Twenty-two per cent of respondents said they could not understand their lessons as far away from school. The participants mentioned that they would often study in the library or with their peer groups in school, which immensely helped them clarify doubts, but due to their schools' closure, they were missing those amenities. 13.5 per cent of respondents mentioned that they preferred offline to online classes as they felt more comfortable in that medium. A sudden shift in a medium within a short period has definitely increased the level of difficulty as there were many technicalities that they had to follow to get their doubts clarified. 6.17 per cent claimed that they missed interacting and meeting their peer group daily, which was only possible when the school was open, and the rest mentioned that they missed their school teachers as they made them understand their lessons more effectively.

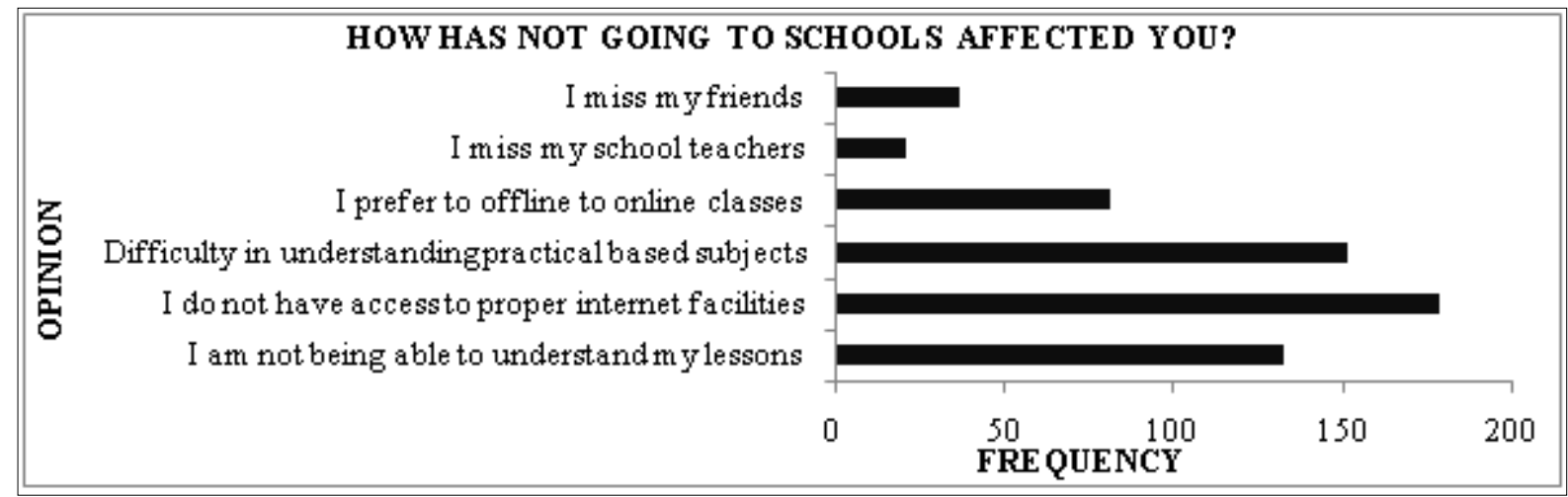

Figure 4: Showing the Ways in which Not Going to School has Affected the Respondents

Source: Based on Primary Survey and Computed by the Author

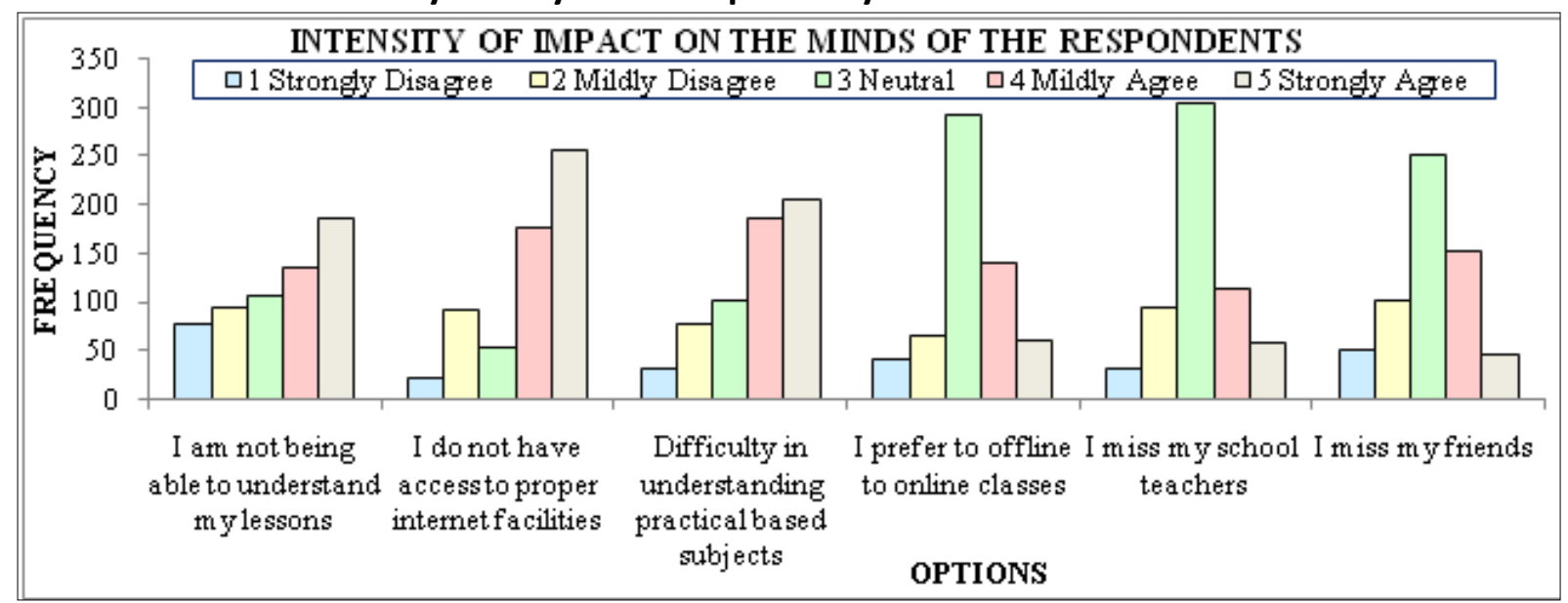

Figure 5: Showing the Intensity of the Impact on the Respondents (School) Source: Based on Primary Survey and Computed by the Author

Further, when the respondents were asked to rate each of the sub-indicators on a five-point scale (please refer to Figure 5). 53.67 per cent of respondents agreed to the statement 'strongly agreed' that they could not understand their lessons, and only 28.5 per cent of respondents disagreed with the statement saying that with the help of internet facilities and online classes, it was quite sufficient for them. Then the respondents were asked to rate their opinion about not having proper internet facilities, to which 72.33 per cent agreed to the statement 
saying that they did not have adequate internet facilities at home. Hence, they could not uninterruptedly attend the online classes, which also affected their regularity and only 18.67 per cent disagreed with this statement. Thirdly, the respondents were asked to rate their opinion if it was difficult for them to understand the practical based subject; in response to this question, 65.17 per cent agreed to it, and only 18 per cent disagreed with it. Fourthly, when the respondents were asked about their offline preference for online classes, most of the respondents remained neutral in their opinion. Then the respondents were asked if they missed their teachers teaching the respective subjects to them back at school and their friends, to which a more significant percentage of students agreed to the statement as opposed to those who said otherwise.

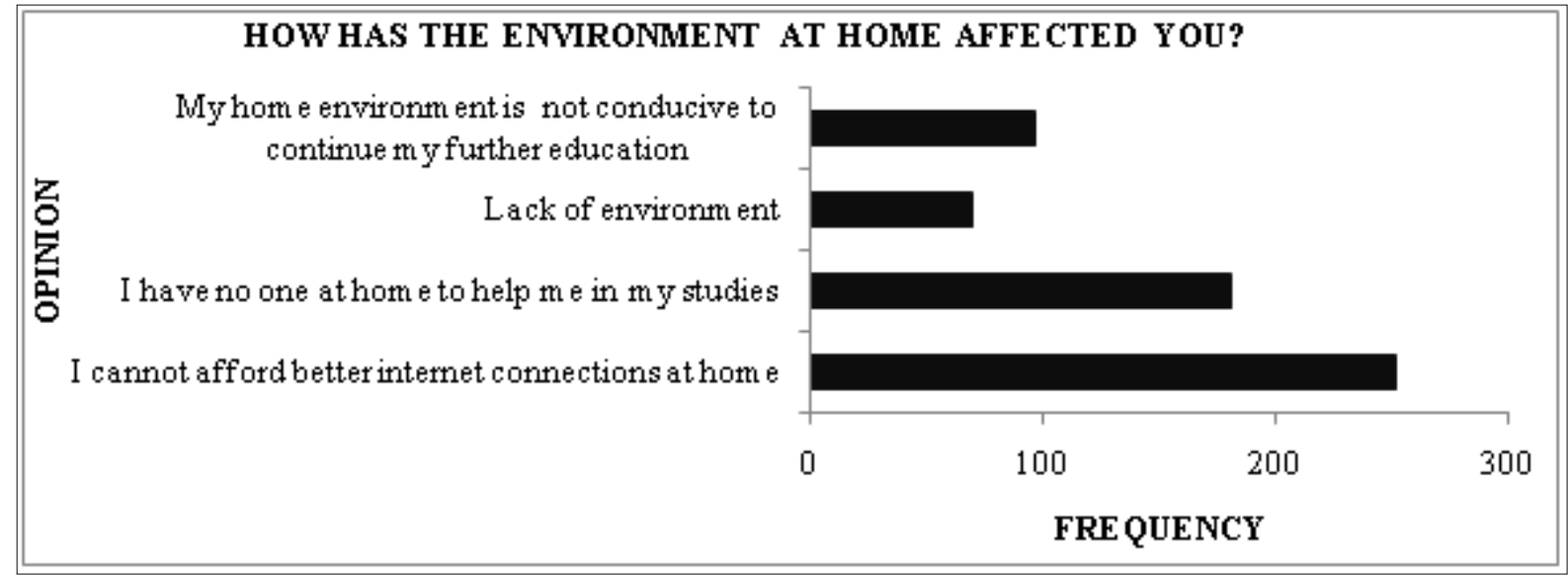

Figure 6: Showing the Ways in Which the Environment Back at Home has Affected the Students

Source: Based on the Primary Survey and Computed by the Author

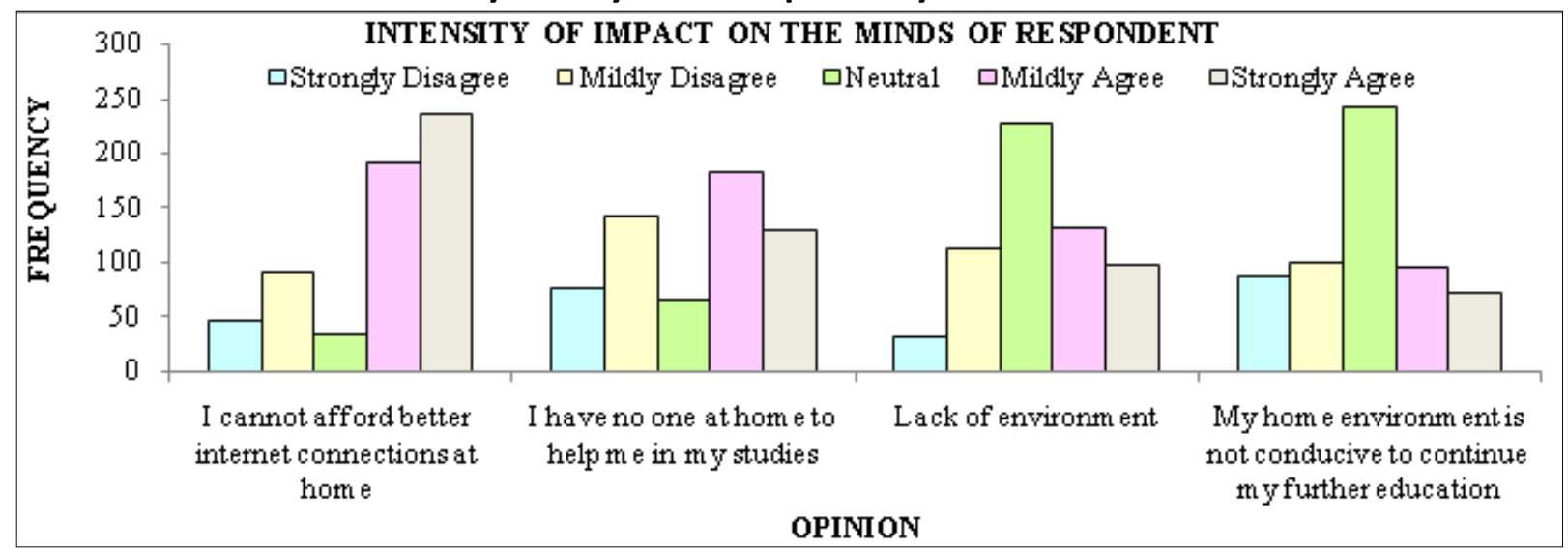

Figure 7: Showing the Intensity of the Impact on the Respondents (Home)

Source: Based on the Primary Survey and Computed by the Author

\section{Home}

The respondents were asked to rank the most critical reason among the various factors related to their home environment, which affected them (please refer to Figure 6). Forty-two per cent of the respondents said that they could not afford better internet connections at home, which disrupted the connectivity and became a primary reason to not benefit from online classes. 30.17 per cent responded to not having anyone at home who could continuously assist and guide them with their studies. 16.17 per cent respondents said that their home environment was not conducive to continue their further education as they had to help out in their household chores regularly; other than this, various types of distractions posed a hindrance and made it difficult for them to concentrate for a prolonged period. 11.67 per cent of respondents stated that the lack of a proper and 
competitive environment at home as a significant reason for the problem. Further on, the respondents were asked to rate each of the sub-indicators on a five-point scale (refer to Figure 7). Firstly, when the respondents were asked if they could not afford better internet connections at home; in response to this, 237 respondents and 191 respondents strongly and mildly agreed to the statement, respectively. They stated that they could not afford better internet facilities at home due to financial, infrastructural constraints, and only 23 per cent disagreed. Secondly, 21.5 per cent of respondents strongly agreed, and 30.67 per cent mildly agreed, stating that there was nobody back at home who could continuously guide and assist them in their studies, the way their teachers in their schools would. However, 12.83 per cent and 23.83 per cent strongly and mildly disagreed with the statement based on their personal experiences. Thirdly, when the respondents were asked if there was a lack in a competitive environment, a greater percentage share of respondents agreed to that statement compared to those who disagreed with the statement.

\section{Shift in the Medium}

The respondents were asked to rank the most important reasons why they felt that this shift in the medium poses a problem for them in their studies. Sixteen per cent said that they could not attend the classes due to connectivity issues as most of the time, either the server tends to become very slow, or the internet connection gets disrupted between the classes. 14.17 per cent said that they tend to get lured towards other distractions and switch over to social media platforms while attending online classes. 12.5 per cent said that their mobile or laptop tends to get overheated at times and stops functioning in between the classes. 9.5 per cent said that they tend to lose interest while studying in their virtual classes. 9.17 per cent said that they preferred offline to online classes as it was easier for them to understand in the former. The respondents also mentioned that they were facing problems while clarifying their doubts, and often in the interactive sessions, some students tend to ask irrelevant questions that prolong the class. 5.5 per cent also faced problem while asking questions as there are different set of technicalities that have to be done prior to it, and 6.17 per cent respondents mentioned that sometimes accessing the live sessions was also difficult. 7.17 per cent said that often due to connectivity difficulties, the voice and image clarity gets distorted. As a result, it affects their understanding, and 3.83 per cent has mentioned that they tend to get distracted easily.

Then the respondents were asked to rate each one of the sub-indicators on a five-point scale. A greater percentage share of respondents stated that accessibility and connectivity was an issue for them. When the respondents were asked if they faced a problem while clarifying their doubts, the respondents had mixed opinion where almost an equal percentage share of students spoke for and against the topic. Following this question, the respondents were asked if they tended to lose their interest while attending online classes, to which a more significant share of respondents agreed to it rather than disagreeing with the statement. When the respondents were asked if they tended to switch over to social media while attending lessons, almost 60 per cent of the respondents replied in affirmative to this question. On asking the respondents if their mobile and laptop tends to get overheated and at times if the software crashes in between the lessons, 64.67 per cent mildly agreed to this statement, and 25.17 per cent strongly agreed to it. This signifies that most of the respondents were affected because of this reason.

\section{How has the Pandemic Affected the Future Plan, Ambition and Decision to Study Abroad of the Respondents}

The respondents were asked whether this pandemic has affected the students' future plans and ambitions (refer to Figure 8). In response to this only 3.5 per cent strongly disagreed, 15.17 per cent mildly disagreed, 38.5 per cent mildly agreed, 19.33 per cent strongly agreed and 23.5 per cent remained undecided. The respondents were asked whether they wanted to study 
abroad before the pandemic. In response to this question, most of the respondents mentioned that they were undecided, 14.5 per cent replied in affirmative, and 15.5 per cent of the respondents mentioned that they did not have any such interest. Then those who said yes were asked the question as to whether they wanted to study abroad. In response to this question, 40.23 per cent wanted to defer their higher studies until next year, 39.08 per cent said that now they did not want to study abroad, and 20.69 per cent said that they wanted to study in a less risky country. When the respondents were asked why the respondents had changed their opinion, 26.97 per cent strongly agreed, 20.01 per cent mildly agreed, 7.83 per cent mildly disagreed, 8.05 per cent strongly disagreed 14.79 per cent remained neutral to the opinion. When the respondents were asked if they could not afford the course fee and are unwilling to take a loan for the purpose, to this 20.91 per cent strongly agreed, 16.53 per cent mildly agreed that the respondents mildly agreed to the statement. Adding on to this, 40.02 per cent agreed to the statement saying that their family was unwilling to leave them abroad. On asking them the reason, roughly about 49.59 per cent of respondents said that they were unsure if they would get a job at the end of their course. Hence, they were unwilling to pursue that course in a foreign country. On asking the respondents if they were interested in pursuing the same subjects as they had initially planned, the respondents were mostly divided in their opinion. Further on, when the respondents who previously wanted to go abroad for their studies were asked if they were unable to finance their education, in response to this question, a more significant percentage share of respondents replied in affirmative. Some of the respondents had also mentioned that studying abroad has increased their investment, but it was not profitable for them as even after the high investment, it has become a low return option for them.

It can be concluded by saying that the pandemic has significantly altered the students' academic decision; a more significant percentage share of respondents has agreed to this statement in addition to this 73.83 per cent said that it has negatively affected them.

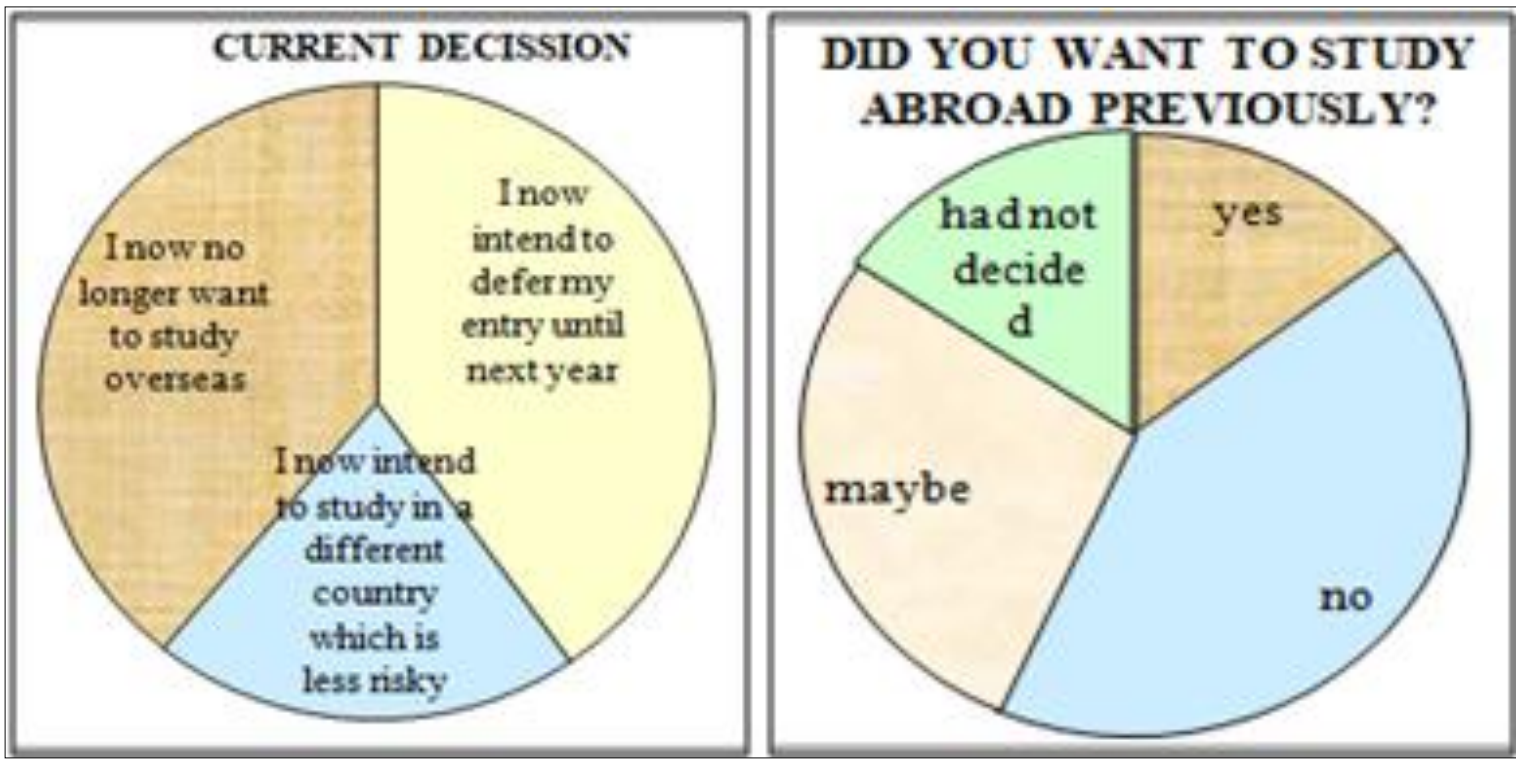

Figure 8: Showing the Past and the Present Decision of the Students Who Wanted to Study Abroad

Source: Based on the Primary Survey and Computed by the Author

\section{Conclusion}

This study aimed at examining the effect of COVID-19 on students studying In the Secondary and Higher Secondary Level in Kolkatta. In doing so, it unveiled the constraints and challenges that the students have been facing amid COVID19. The findings of this study will definitely help 
frame better school functioning policies in the future.

\section{References}

Abdulamir, A.S. \& Hafidh, R.R. (2020). The Possible Immunological Pathways for the Variable Immunopathogenesis of Covid-19 Infections Among Healthy Adults, Elderly And Children, Electronic Journal of General Medicine, 17(4), 1-4, https://doi.org/10.29333/ejgm/7850

Academic Impact. (2020, May 4). Covid-19 And Higher Education: Learning to Unlearn to Create Education for the Future. Academic Impact. Https://Academicimpact.UN.Org/Content/Covid -19-And-Higher-Education-Learning-UnlearnCreate-Education-Future.

Ackerman, J. M., Becker, D. V., Mortensen, C. R., Sasaki, T., Neuberg, S. L., \& Kenrick, D. T. (2009). A Pox on the Mind: Disjunction of Attention and Memory in the Processing of Physical Disfigurement. Journal of Experimental Social Psychology, 45 (3), 478 -485, doi: 10.1016/j.jesp.2008.12.008

Aneshensel, C. S. (1992). Social Stress: Theory and Research. Annual Review of Sociology, 18, 15- 38 .

https://doi.org/10.1146/annurev.so.18.080192. 000311

Bassett, R.M., \& Arnhold, N. (2020). Covid-19's Immns Impact on Equity in Tertiary Education. World Bank: Education For Global Development. https://tinyurl.com/p9eumdac

Business Insider India. (2020, May 13). Indian Stem Aspirants Reconsider Their Plans to Pursue Higher Education Abroad Due to Covid19 Pandemic. India. Business Insider. https://tinyurl.com/f9jr758z

Chahrour, M., Assi, S., Bejjani, M., Nasarallah, A. A., Salhab, H., Fares, M., Khachfe, H. H. (2020, March 21). A Bibliometric Analysis of Covid-19 Research Activity: A Call for Increased Output. Cureus, 12(3), 1-8. Doi 10.7759/cureus.7357. Chen, Q., Liang, M., Li Y., Guo, J., Fei, D., Wang. L., He, Li., Sheng, C., Cai, Y., Li, X., Wang, J., Zhang, Z. (2020). Mental Health Care for Medical Staff In China During The Covid-19
Outbreak. The Lancet Psychiatry, 7(4), 1-2, DOI:https://doi.org/10.1016/S22150366(20)30078-X

Choudhary, R. (2020, April 16). E-Learning: Covid-19 Pandemic: Impact And Strategies For Education Sector In India. Economic Times news. https://tinyurl.com/4sn4wm6x

Chunfeng, X. (2020). A Novel Approach of Consultation on 2019 Novel Coronavirus (Covid19)- Related Psychological and Mental Problems: Structured Letter Therapy. Psychiatry Investigation, 17(2), 175- 176, https://doi.org/10.30773/pi.2020.0047

Cowling, B. J., Ng, D.M., Ip, D., K., Liao, Q., Lam, Wendy, W. T., Wu, Joseph T., Lau, Joseph T.F., Griffiths, S. M., Fielding, R. (2010). Community Psychological and Behavioural Responses Through the First wave of the 2009 Influenza A (H1N1) Pandemic in Hong Kong. The Journal Of Infectious Diseases, 202(6), 867-876, https://doi.org/10.1086/655811

Depietro, A. (2020). Here's A Look at the Impact Of Coronavirus (Covid-19) on Colleges and Universities In The U.S., United States. https://tinyurl.com/3dbdzcs4

Duan, L. \& Gang, Z. (2020). Psychological Interventions for People Affected by the Covid19 Epidemic. The Lancet Psychiatry. 7(4). https://doi.org/10.1016/ S2215-0366(20)300730

Education Today News (2020, April 7). How Is the Covid-19 Pandemic Affecting Education All Over The World? Education Today News. https://tinyurl.com/3phcth3s

Education Today News (2020). Covid-19: 4 Negative Impacts And 4 Opportunities Created For Education. New Delhi: Education Today News.

Farooqui, S. (2020, May 1). Education in the Time In The Time Of Covid-19: How Institutions And Students Are Coping. Business Standard News. https://tinyurl.com/n84y9dds

Gabriels, W. \& Benke, R. A. (2020). Student Exchanges in Times Of Crisis. Europe: Erasmus Student Network Aisbl.https://tinyurl.com/5n773k2 
Icef Monitor (2020). Measuring Covid-19's Impact On Higher Education. U.S.: Icef Monitior. https://tinyurl.com/bzsvz7zj

Jamieson, S. (2017). Likert Scale. Encyclopaedia Britannica, 1. https://www.britannica.com/print/article/1085 454

Kasrekar, D. \& Tapaaswi, G. W. (2020, May, 16). Impact of Covid-19 On Education System In India. India. https://tinyurl.com/p3dyzkb2

Khan, S., Siddique, R., Li, H., Ali, A., Shereen, M.A., Bashir, N., Xue, M. (2020). Impact Of Coronavirus Outbreak On Psychological Health. Journal of Global Health, 10(1), 1-5. https://doi.org/10.7189/JOGH.10.010331

Khosravi, M. (2020). Perceived Risk Of Covid-19 Pandemic: The Role Of Public Worry And Trust. Electronic Journal Of General Medicine, 17(4), 12. https://doi.org/10.29333/ejgm/7856

Kothari, C.R. (2004). Research Methodologyresearch And Techniques. New Delhi: New Age International $(\mathrm{P})$ Limited.

Lai, C. C., Shih, T. P., Ko, W. C., Tang, H. J. \& Hsueh, P. R. (2020). Severe Acute Respiratory Syndrome Coronavirus 2 (Sars-Cov-2). International Journal of Antimicrobial Agents, 55(3), 5- 15. 10.1016/j.ijantimicag.2020.105924

Langella, M. (2020). Covid-19 And Higher Education: Some Of The Effects On Students And Institutions And How To Alleviate Them. London: British Politics And Policy At Lse. https://tinyurl.com/2hpjm55n

Li, S., Wang, Y., Xue, J., Zhao, N. \& Zhu, T. (2020, March 19). The Impact of Covid- 19 Epidemic Declaration On Psychological Consequences: A Study On Active Weibo Users. International Journal On Environmental Research And Public Health, 17(6), 1-7. Doi:10.3390/ijerph17062032

Mortensen, C. R., Becker, D. V., Ackerman, J. M., Neuberg, S. L. \& Kenrick, D.T. (2010). Infection Breeds Reticence: The Effects Of Disease Salience on Self Perceptions of Personality and Behavioral Avoidance Tendencies. Psychological Science, 21(3), 440447. doi: 10.1177/0956797610361706
Norris, F. H., Friedman, M. J. \& Watson, P. J. (2002). 60, 000 Disaster Victims Speak: Part IISummary and Implications of the Disaster Mental Health Research. Psychiatry. 65(3), 240249. doi:10.1521/psyc.65.3.240.20169

North East Now (2020, May 13). Covid-19 Pandemic To Impact Study Abroad Plans Of Indian Students. https://tinyurl.com/yexp9tav Sahani, U. (2020, March 6). Covid-19 in India: Education Disrupted and Lessons Learned. https://tinyurl.com/ytjmm8u8.

Sahu, P. (2020, April 4). Closure Of Universities Due to Coronavirus Disease 2019 (Covid-19): Impact on Education and Mental Health of Students And Academic Staff. Cureus, 12(4), 16. Doi:10.7759/cureus.7541

Schaller, M. \& Murray, D. R. (2008). Pathogens, Personality and Culture: Disease Prevalence Predicts Worldwide Variability in Sociosexuality, Extraversion and Openness to Experience. Journal of Personality and Social Psychology, 95(1), 212-221. Doi: 10.1037/00223514.95.1.212

Schaller, M., Murray, D. R. \& Bangerter, A. (2015). Implications of the Behavioural System for Social Behaviour and Human Health in the Modern World. Philosophical Transactions B, 370, 2-10. http://dx.doi.org/10.1098/rstb.2014.0105 Slovic, P. (1987). Perception of Risk. Science, 236. 280- 285. Doi:10.1126/science.3563507

Terrizzi Jr., J. A., Shook, N. J. \& Mcdaniel, M. A., (2013). The Behavioral Immune System and Social Conservatism: A Meta-Analysis. Evolution And Human Behavior, 99- 107.

http://dx.doi.org/10.1016/j.evolhumbehav.201 2.10 .003

The Economic Times (2020, April 5). Study Abroad Dreams Shattered Or Delayed Due To Covid-19, Students Look For Plan B. https://tinyurl.com/ffbkynau

The New Indian Express (2020, May 1). Covid-19 and the Blow to the Education Sector. https://tinyurl.com/59za2fbd 
The North East Today (2020, March 6). Covid-19 and its Impact on Students in Meghalaya: Myths \& Reality. https://tinyurl.com/mazs7dt9

Weber, E. U., Anderson C. J. \& Birnbaum, M. H. (1992). A Theory Of Perceived Risk And Attractiveness. Organizational Behaviour and Human Decision Processes, 52, 492-523. Doi: 10.1016/0749-5978(92)90030-B

Weerd, W. V., Timmermans, D. R, Beaujean, D. J., Oudhoff, J. \& Steenbergen, J. E. (2011). Monitoring the Level of Government Trust, Risk Perception And Intention of the General Public To Adopt Protective Measures During the Influenza A (H1N1) Pandemic in the Netherlands. BMC Public Health, 11, 1-12. doi:10.1186/1471-2458-11-575

World Health Organisation (2020). WHO Director General's Opening Remarks at the Media Briefing on Covid-19- 11 March 2020. World Health Organisation. https://tinyurl.com/373f5jf7

Yang , Y., Li, W., Zhang, L., Cheung, T. \& Xiang, Y. T. (2020) Mental Health Services for Older Adults in China During the Covid-19 Outbreak. Psychiatry, 1. https://doi.org/10.1016/ S22150366(20)30079-1

Yanping, B., Yankun, S., Shiqiu, M., Jie, S. \& Lin, L. (2020). 2019-Ncov Epidemic: Address Mental Health Care To Empower Society. The Lancet, 395, 1. https://doi.org/10.1016/ S01406736(20)30309-3
Yoko, I., Chapman, G. B., Meyers, L. A., Li, M. \& Galvani, A. P. (2010). The Dynamics Of Risk Perceptions and Precautionary Behaviour in Response to 2009 (H1N1) Pandemic Influenza. BMC Infectious Diseases, 2010. 10, 211.https://doi.org/10.1186/1471-2334-10-296

Zee News (2020). Coronavirus Covid-19 Pandemic To Impact Study Abroad Plans Of Over 48\% Indian Students: Qs Report. New Delhi, India: Zee News. https://tinyurl.com/cj34n9sw

\section{Conflict of Interest}

The author declares that there is no conflict of interest.

\section{Acknowledgement}

The author is extremely grateful to the anonymous reviewers and the editors for their valuable comments, suggestion and assistance. I would like to express my heartfelt gratitude towards my father Mr Raghunath Sinha and my mother Mrs Papia Sinha for their inspiration. The author also expresses her gratitude to all the respondents who have given their consent and participated in the survey.

\section{About the Author}

Sudarshana Sinha is currently pursuing her PhD from the Indian Institute of Technology, Kharagpur, Department of Humanities and Social Sciences. She has five research papers published in various international journals. She is interested in topics related to education, urban studies and peri-urban areas. 